\title{
Anti-Oxidant and Anti-Cancer Potential of Siddha Medicine Thayiriya Vendhan Chendhuram (TVC) using MTT Assay against MCF- 7 (Human Breast Adenocarcinoma)
}

\author{
Authors \\ Vaniswari D.S ${ }^{* 1}$, Arunachalam $\mathrm{K}^{2}$ \\ ${ }^{* 1}$ Post Graduate, Department of Kuzhanthai Maruthuvam, Tamil Nadu \\ ${ }^{2}$ Research Associate (Siddha), Siddha Clinical Research Unit, Tirupati, Andhra Pradesh, India \\ *Corresponding Author \\ Vaniswari D.S \\ ${ }^{1}$ Post Graduate, Department of Kuzhanthai Maruthuvam, Tamil Nadu, India
}

\begin{abstract}
Objective: The objective of this study was to evaluate the invitro anti oxidant potential and anticancer efficacy of Thayiriya vendhan chendhuram -TVC.

Methods: We have evaluated scientifically TVC for its anti cancer efficacy in human breast adenocarcinoma through in vitro cell lines studies. The viability of cells was evaluated by direct observation of cells by Inverted phase contrast microscope and followed by MTT assay method.In this study, anti oxidant potential of TVC was also evaluated with gallic acid as comparison.

Results and Conclusion: From the result of the present in-vitro study it was concluded that the test drug TVC possess considerable anti-oxidant and anti-cancer activity. The study is the first step in the scientific validation of TVC for anti oxidant and anticancer potential and in use against breast adenocarcinoma.

Keywords: Breast cancer, Siddha oncology, Anti oxidant drug, Thayiriya vendhan chendhuram, herbo metallic drug.
\end{abstract}

\section{Introduction}

The Siddha medicine is a renowned holistic system of traditional medicine emphasizing curative and preventive measures. Siddha system has developed a rich and unique treasure of drug knowledge in which use of metals and minerals is very much advocated.

Description about Cancer and its risk factors: Cancer is one of the most life threatening diseases and possess many health hazard in both developed and developing countries $^{2}$, characterized by irregular proliferation of cells. Every biological change can be seen when a normal cell progresses to cancerous one. Since many treatments are available for cancer therapy still cancer is the $2^{\text {nd }}$ leading cause of death in the globe, Chemotherapy and modern drugs for treatment of cancer reported more side effects in the patients treated. Every year, millions of people are diagnosed with cancer, leading to death ${ }^{3}$. Cancer kills about 3500 million people annually all over the world; it accounts more than $2-3 \%$ of the annual deaths recorded worldwide ${ }^{4}$. Treatment of Cancer is somewhat successful with chemopreventive 
agents but usage is left against risk because of their toxicity ${ }^{5,6}$. Therapeutic potentials of metalbased compounds date back to ancient time. ${ }^{7}$ During this period, the ancient Assyrians, Egyptians and Chinese knew about the importance of using metal-based compounds in the treatment of diseases, ${ }^{7}$ such as the use of cinnabar (mercury sulfide) in the treatment of ailments. ${ }^{7}$ The advent of "theoretical science", by Greek philosophers (Empedocles and Aristotle) in the 5th and 4th century $\mathrm{BC}^{7}$ boosted the knowledge of metalbased compounds as therapeutic agents. This was supported by the information handed down by Pliny and Aulus Cornelius Celsus (Roman physicians) on the use of cinnabar in the treatment of trachoma and venereal diseases. ${ }^{7}$

Scope of metal complexes in the treatment of cancer: Therapeutic potential of metal complexes in cancer therapy has attracted a lot of interest mainly because metals exhibit unique characteristics, such as redox activity, variable coordination modes and reactivity toward the organic substrate. ${ }^{8}$ These properties become an attractive probe in the design of metal complexes ${ }^{8}$ that selectively bind to the biomolecular target with a resultant alteration in the cellular mechanism of proliferation.

\section{WHO statistical analysis -Breast cancer 2018:}

Breast cancer is the most frequent cancer among women, impacting 2.1 million women each year, and also causes the greatest number of cancerrelated deaths among women. In 2018, it is estimated that 627,000 women died from breast cancer - that is approximately $15 \%$ of all cancer deaths among women. While breast cancer rates are higher among women in more developed regions, rates are increasing in nearly every region globally ${ }^{14}$.

\section{Experimental Section}

\section{Details regarding the sample}

Thaiyeria Vendhan Chendooram is a siddha formulation mentioned in the text "Siddha Maruthuva Cinnnthamani ${ }^{15}$ ", for the management of anaemia, spleenomegaly, gastric ulcer and carcinoma. The ingredients of Thaiyeria Vendhan Chendooram (TVC) were purified, prepared as per the siddha materica medical procedures ${ }^{15}$.

\section{Materials and Methods}

\section{Anti-Cancer Activity}

MCF- 7 (Human Breast Adenocarcinoma) cells was initially procured from National Centre for Cell Sciences (NCCS), Pune, India and maintained Dulbecco's modified Eagles medium, DMEM (Sigma aldrich, USA).The cell line was cultured in $25 \mathrm{~cm}^{2}$ tissue culture flask with DMEM supplemented with $10 \%$ FBS,Lglutamine, sodium bicarbonate (Merck, Germany) and antibiotic solution containing: Penicillin (100U/ml), Streptomycin $(100 \mu \mathrm{g} / \mathrm{ml})$, and Amphoteracin B $(2.5 \mu \mathrm{g} / \mathrm{ml})$. Cultured cell lines were kept at $37^{\circ} \mathrm{C}$ in a humidified $5 \% \quad \mathrm{CO}_{2}$ incubator (NBS Eppendorf, Germany). The viability of cells was evaluated by direct observation of cells by Inverted phase contrast microscope and followed by MTT assay method.

\section{Cells seeding in 96 well plate}

Two days old confluent monolayer of cells were trypsinized and the cells were suspended in $10 \%$ growth medium, $100 \mu \mathrm{l}$ cell suspension $\left(5 \times 10^{4}\right.$ cells/well) was seeded in 96 well tissue culture plate and incubated at $37^{\circ} \mathrm{C}$ in a humidified $5 \%$ $\mathrm{CO}_{2}$ incubator.

\section{Preparation of compound stock}

$1 \mathrm{mg}$ of sample was weighed and dissolved in $1 \mathrm{~mL}$ DMEM using a cyclomixer. The sample solution was filtered through $0.22 \mu \mathrm{m}$ Millipore syringe filter to ensure the sterility.

\section{Anticancer Evaluation}

After 24 hours the growth medium was removed, freshly prepared each compounds in 5\% DMEM were five times serially diluted by two-fold dilution $(100 \mu \mathrm{g}, 50 \mu \mathrm{g}, 25 \mu \mathrm{g}, 12.5 \mu \mathrm{g}, 6.25 \mu \mathrm{g}$ in $500 \mu 1$ of $5 \%$ DMEM) and each concentration of $100 \mu 1$ were added in triplicates to the respective wells and incubated at $37^{\circ} \mathrm{C}$ in a humidified $5 \%$ $\mathrm{CO}_{2}$ incubator. Non treated control cells were also maintained. 


\section{Anticancer Assay by Direct Microscopic observation}

Entire plate was observed after 24 hours of treatment in an inverted phase contrast tissue culture microscope (Olympus CKX41 with Optika Pro5 CCD camera) and microscopic observation were recorded as images. Any detectable changes in the morphology of the cells, such as rounding or shrinking of cells, granulation and vacuolization in the cytoplasm of the cells were considered as indicators of cytotoxicity.

\section{Anticancer Assay by MTT Method}

Fifteen mg of MTT (Sigma, M-5655) was reconstituted in $3 \mathrm{ml}$ PBS until completely dissolved and sterilized by filter sterilization. After 24 hours of incubation period, the sample content in wells were removed and $30 \mu \mathrm{l}$ of reconstituted MTT solution was added to all test and cell control wells, the plate was gently shaken well, then incubated at $37^{\circ} \mathrm{C}$ in a humidified $5 \%$ $\mathrm{CO}_{2}$ incubator for 4 hours. After the incubation period, the supernatant was removed and $100 \mu 1$ of MTT Solubilization Solution (Dimethyl sulphoxide, DMSO, Sigma Aldrich, USA)was added and the wells were mixed gently by pipetting up and down in order to solubilize the formazan crystals. The absorbance values were measured by using microplate reader at a wavelength of $540 \mathrm{~nm}$ (Laura B. Talarico et al., 2004).The percentage of growth inhibition was calculated using the formula:

$$
\% \text { of viability }=\frac{\text { Mean OD Samples } \mathrm{x} 100}{\text { Mean OD of control group }}
$$

\begin{tabular}{|l|c|c|c|c|c|}
\hline $\begin{array}{l}\text { Sample Concentration } \\
(\boldsymbol{\mu g} / \mathbf{m L})\end{array}$ & OD value I & OD value II & OD value III & Average OD & $\begin{array}{c}\text { Percentage } \\
\text { Viability }\end{array}$ \\
\hline Control & 1.4872 & 1.4369 & 1.4015 & 1.4419 & 100.00 \\
\hline Sample code: Thayiriya vendhan chendhuram \\
\hline 6.25 & 0.9632 & 0.9618 & 0.9662 & 0.9637 & 66.84 \\
\hline 12.5 & 0.9444 & 0.9471 & 0.9436 & 0.9450 & 65.54 \\
\hline 25 & 0.8450 & 0.8469 & 0.8471 & 0.8463 & 58.70 \\
\hline 50 & 0.7820 & 0.7763 & 0.7749 & 0.7777 & 53.94 \\
\hline 100 & 0.6849 & 0.6852 & 0.6814 & 0.6838 & 47.43 \\
\hline
\end{tabular}

\section{LC50 Value: $80.291 \mu \mathrm{g} / \mathrm{mL}$ (Calculated using ED50 PLUS V1.0 Software)}

Role of Antioxidant: Antioxidants significantly delay or prevent oxidation of oxidizable substrates when present at lower concentrations than the substrate $^{9}$. Antioxidants can be synthesized in vivo (e.g., reduced glutathione (GSH), superoxide dismutase (SOD), etc.) or taken as dietary antioxidants ${ }^{10}$. Antioxidants stabilize or deactivate free radicals, often before they attack targets in biological cells ${ }^{11}$. Recently interest in naturally occurring antioxidants has considerably increased for use in food, cosmetic and pharmaceutical products, because they possess multifacetedness in their multitude and magnitude of activity and provide enormous scope in correcting imbalance ${ }^{12,13}$. Free radicals and other oxidants have gained importance in the field of biology due to their central role in various physiological conditions as well as their implication in a diverse range of diseases. The free radicals, both the reactive oxygen species (ROS) and reactive nitrogen species (RNS), are derived from both endogenous sources (mitochondria, peroxisomes, endoplasmic reticulum, phagocytic cells etc.) and exogenous sources (pollution, alcohol, tobacco smoke, heavy metals, transition metals, industrial solvents, pesticides, certain drugs like halothane, paracetamol, and radiation). Free radicals can adversely affect various important classes of biological molecules such as nucleic acids, lipids, and proteins, thereby altering the normal redox status leading to increased oxidative stress ${ }^{16}$ 


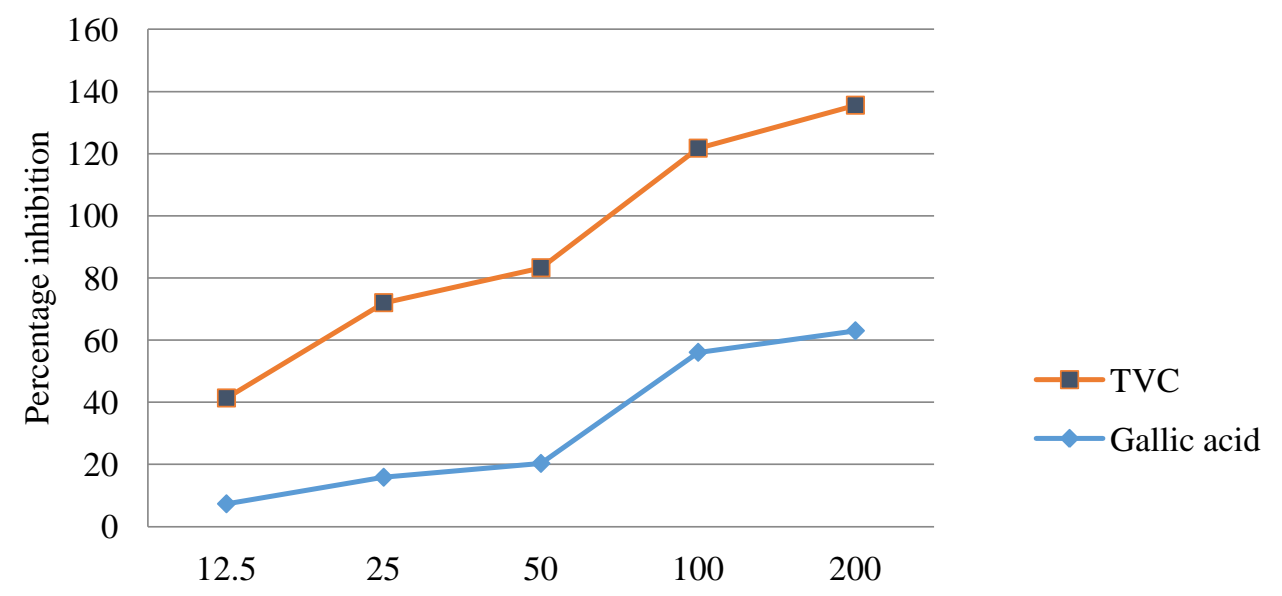

Evaluation of Anti Oxidant Potential -TVC

\begin{tabular}{|l|c|c|}
\hline CONCENTRATIONS $(\boldsymbol{\mu g} / \mathbf{m l})$ & GALLIC ACID & TVC \\
\hline 12.5 & $7.29 \%$ & $34.05 \%$ \\
\hline 25 & $15.83 \%$ & $56.18 \%$ \\
\hline 50 & $20.28 \%$ & $62.96 \%$ \\
\hline 100 & $56.04 \%$ & $65.69 \%$ \\
\hline 200 & $62.98 \%$ & $72.57 \%$ \\
\hline
\end{tabular}

\section{Conclusion}

From the result of the present in-vitro study it was concluded that the test drug TVC possess considerable anti-oxidant and anti-cancer Activity.

\section{Acknowledgment}

The authors are thankful to Trivandrum Biogenix Research Center for providing the facilities.

\section{Conflicts of Interest}

The authors declare that they have no conflicts of interest.

\section{References}

1. Gupta AK and Tandon N. Reviews on Indian Medicinal Plants. New Delhi: Indian Council of Medical Research, 2004.

2. Izevbigie EB Discovery of water-soluble anticancer agents (edotides) from a vegetable found in Benin City, Nigeria. Exp Biol Med (Maywood), 2003; 228:293298.
3. Om Prakash, Amit Kumar, Pawan Kumar, and Ajeet, "Anticancer Potential of Plants and Natural Products: A Review." American Journal of Pharmacological Sciences 1, no. 6 2013; 104-115. doi: 10.12691/ajps-1-6-1.

4. Krishnamurthi K. Screening of natural products for anticancer and antidiabetic properties. Health Administrator. XX ,2000;(1\&2): 69.

5. K. Srinivas; A.J Afolayan. Current Science, 2007; 92, 906-8.

6. K.Kathiresan; N.S Boopathy; S. Kavitha. Natural Product Radience, 2006; 5, 11519.

7. Norn S, Permin H, Kruse E, Kruse PR. Mercury a major agent in the history of medicine and alchemy. Dan Medicinhist Årboq. 2008;36:21-40. [PubMed] [Google Scholar]

8. Frezza M, Hindo S, Chen D, et al. Novel metals and metal complexes as platforms 
for cancer therapy. Curr Pharm Des. 2010;16(16):1813-1825. [PMC free article] [PubMed] [Google Scholar]

9. Halliwell B. Biochemistry of oxidative stress. Biochem Soc Trans. 2007; 35:1147-50.

10. Sies H. Oxidative stress: oxidants, antioxidants. Exp Physiol. 1997; 82:29195.

11. Halliwell B, Gutteridge JMC: Formation of thiobarbituric acid reactive substances from deoxyribose in the presence of iron salts: the role of superoxide and hydroxyl radicals. FEBS Lett. 1981, 128: 347-352.

12. Gulcin I: Antioxidant activity of food constituents:an overview. Arch Toxicol. 2012, 86: 345-391.

13. Gocer H, Gulcin I: Caffeic acid phenethyl ester (CAPE): correlation of structure and antioxidant properties. Int J Food Sci Nutr. 2011, 62: 821-825.

14. WHO PEN Protocol 4.1 Assessment and referral of women with suspected breast cancer at primary health care pdf, $59 \mathrm{~kb}$

15. Siddha Maruthuva Chinthamani Palm leaf manuscript of Tamil Medicine, published by Department of Indian Medicine and Homeopathy, Chennai, First edition 2008, Page.no: 17

16. Alugoju Phaniendra. Free Radicals: Properties, Sources, Targets, and Their Implication in Various Diseases. Indian $\mathrm{J}$ Clin Biochem. 2015 Jan; 30: 11- 26. 